\title{
G

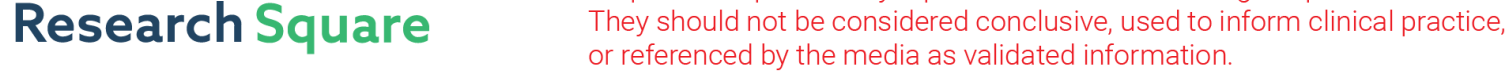 \\ Arterial thrombosis, the unfairly forgotten actor in COVID-19: a case series
}

\section{SERGIO RAMOS CILLAN ( $\nabla$ serraci93@gmail.com)}

Fundación Jiménez Díaz: Hospital Universitario Fundacion Jimenez Diaz https://orcid.org/0000-00021770-7614

\section{LAURA SOLAN BLANCO}

Fundación Jiménez Díaz: Hospital Universitario Fundacion Jimenez Diaz https://orcid.org/0000-00018949-8762

\section{MARTA TOMÁS MALLEBRERA}

Fundación Jiménez Díaz: Hospital Universitario Fundacion Jimenez Diaz

\section{ANA B. ARRIBAS DÍAZ}

Fundación Jiménez Díaz: Hospital Universitario Fundacion Jimenez Diaz

\section{JAVIER CORNAGO NAVASCUES}

Fundación Jiménez Díaz: Hospital Universitario Fundacion Jimenez Diaz

\section{JOSE LUIS LÓPEZ LORENZO}

Fundación Jiménez Díaz: Hospital Universitario Fundacion Jimenez Diaz

\section{MARIA PILAR LLAMAS SILLERO}

Fundación Jiménez Díaz: Hospital Universitario Fundacion Jimenez Diaz

\section{Research Article}

Keywords: COVID-19, arterial thrombosis, right ventricle thrombus, acetylsalicylic acid, thromboprophylaxis

Posted Date: May 24th, 2021

DOI: https://doi.org/10.21203/rs.3.rs-535712/v1

License: (c) (1) This work is licensed under a Creative Commons Attribution 4.0 International License. Read Full License 


\section{Abstract}

Background. - It is known that patients with COVID-19 are at increased risk of thrombosis. Although COVID-19 infection primarily affects the lower respiratory tract system, emerging reports suggest direct and indirect cardiovascular complications. However, the key mechanisms under thrombosis development at great arterial vessels are still unclear.

Case presentation. - We report the cases of 4 patients who were admitted to our hospital and suffered from arterial thrombotic complications. All of them were older than 60 years and only 1 did not have cardiovascular risk factors. It should be noted that days prior to the diagnosis of arterial thrombosis, 3 of the 4 patients were under anticoagulant treatment. It is also interesting that in contrast to already known typical microvascular locations, our patients suffered from large arterial vessels thrombosis. Furthermore, none of them would present with severe respiratory symptoms.

Conclusions. - The underlying mechanism of COVID-19-associated arterial thrombosis remains unclear and might be independent of the cytokine storm that occurs in patients with COVID-19-associated venous thrombosis. Also, the role of anti-platelets agents as prophylactic treatment in high-risk patients remains unclear. Multicenter clinical trials are necessary to clarify these issues.

\section{Background}

Patients with Coronavirus Disease-2019 (COVID-19) are at increased risk for venous and arterial thrombosis. The inflammatory response and the dysfunction of the vascular endothelium seen in the context of COVID-19 infection may predispose to coagulation disorders and other deleterious complications. It is well known that endothelial injury plays a significant role in COVID-19 related comorbidities such as hypertension, obesity and diabetes. Given the rapidly growing pandemic lived worldwide in the last months, there is an urgent need to measure the rate of thrombotic manifestations associated to COVID-19 and to analyze its impact on survival.

Although COVID-19 infection primarily affects the lower respiratory tract system, emerging reports suggest direct and indirect cardiovascular complications. We report the cases of 4 patients who were admitted to our hospital. None of them presented with severe respiratory symptoms and 3 out of 4 were under antithrombotic treatment. However, all of them suffered from arterial thrombotic complications and needed urgent surgery. Moreover, one of them presented with a right ventricle thrombus, a very rare complication, even in patients with severe pneumonia.

Multiple studies report that microvascular thrombotic and inflammatory processes may play a role in exacerbating acute respiratory distress syndrome (ARDS) and extrapulmonary events in patients suffering from COVID-19, but key mechanisms in large arterial vessels thrombosis is not clear yet.

\section{Case Presentation}


Characteristics of the four patients are detailed in Table 1. As described below, two of them had a history of cancer, and likewise three out of four patients had cardiovascular risk factors. Despite confirming concomitant infection with COVID-19 in all patients, none of them required mechanical ventilation during their hospitalization.

Table 1. - Demographic and clinical characteristics at the time of the thrombotic event. 


\begin{tabular}{|c|c|c|c|c|}
\hline & Case 1 & Case 2 & Case 3 & Case 4 \\
\hline \multicolumn{5}{|l|}{ Baseline characteristics } \\
\hline Age (years) & 63 & 63 & 66 & 85 \\
\hline Gender & male & female & male & female \\
\hline CV disease risk factors & none & $\begin{array}{l}\text { diabetes, } \\
\text { smoking }\end{array}$ & $\begin{array}{l}\text { diabetes, } \\
\mathrm{HT}\end{array}$ & HT \\
\hline Previous cancer & $\begin{array}{l}\text { AML(nd), } \\
\text { bladder(r) }\end{array}$ & cervical(r) & no & no \\
\hline Other background & none & $\begin{array}{l}\text { AF, stroke, } \\
\text { HIV }\end{array}$ & none & $\mathrm{AF}$ \\
\hline \multicolumn{5}{|l|}{ COVID-19 infection } \\
\hline Diagnostic test & PCR & PCR & PCR & PCR \\
\hline ARDS & no & no & no & no \\
\hline Pneumonia & yes & yes & no & yes \\
\hline Treatment & - & - & - & - \\
\hline Low flow 02 therapy & yes & no & no & yes \\
\hline Mechanical ventilation & no & no & no & no \\
\hline Remdesivir & yes & no & no & no \\
\hline Corticoids & yes & no & no & yes \\
\hline Anticoagulation & prophylactic & therapeutic & no & therapeutic \\
\hline Cyclosporine & no & no & no & no \\
\hline Thrombus localization & IAo/Cl/LF/RP/RV & IAo & $\mathrm{CF}$ & $\mathrm{IAo} / \mathrm{Cl}$ \\
\hline Imaging exam & CTA/TTE & CTA & CTA & CTA \\
\hline $\begin{array}{l}\text { Days between infection and } \\
\text { thrombus diagnosis }\end{array}$ & 23 & 20 & 0 & 25 \\
\hline Treatment & $\mathrm{TE}+\mathrm{BAB}+\mathrm{A}$ & BAB & $\begin{array}{l}\mathrm{LFi}+\mathrm{TE} \\
+\mathrm{A}\end{array}$ & TE \\
\hline VTE associated & no & no & no & no \\
\hline Status & dead & alive & alive & alive \\
\hline
\end{tabular}

CV, cardiovascular; HT, hypertension; nd, new diagnosis; r, remission; AF, atrial fibrillation; HIV, human immunodeficiency viruses; PCR, protein-chain-reaction; ARDS, acute respiratory distress syndrome; Ao, aorta; CTA, computed tomographic angiography; TTE, transthoracic echocardiogram; VTE, venous 
thromboembolism; BAB, bifemoral axillary bypass; A, amputation; TE, thrombectomy; IAo, infrarenal aorta; $\mathbf{C l}$, common iliac; LF, left femoral; RP, right popliteal; RV, right ventricle; $\mathbf{C F}$, common femoral; $\mathbf{L F i}$, local fibrinolysis.

Case 1, a 63 years old man, was admitted to our hospital due to asthenia, low oxygen saturation and a previous diagnosis of COVID-19 infection, with pulmonary infiltrates in chest X-ray. He was also diagnosed with acute myeloid leukemia (AML) when cytologist checked his blood smear. Before starting the treatment for his AML and due to the fact that his peripheral blood values were stable, treatment against COVID19 was started. He required low-flow nasal cannula oxygen therapy, intermediate doses of corticosteroids, intravenous remdesivir (200mg the first day and $100 \mathrm{mg}$ for four more days) and lowmolecular-weight heparin (LMWH) as thromboprophylaxis until platelet count dropped below 30,000 per $\mathrm{mm}^{3}$. The initial response to treatment was satisfactory, and oxygen therapy could be suspended. Induction chemotherapy for AML with cytarabine and idarubicin was then started. Two days after removing heparin the patient presented with loss of strength and right lower limb pain. It was very light at the beginning but disabling just 48 hours later. A computed tomographic angiography (CTA) was then requested. Large filling defects were identified in the descending infrarenal abdominal aorta and both common iliac arteries. Blood flow at left femoral and right popliteal arteries was restricted too. Many filling defects causing focus of ischemia in both kidneys were seen in renal polar arteries. Moreover, filling defects were seen in splenic parenchyma. Findings, which are shown in Figure 1, were unlikely related to an embolic origin. A thrombus of uncertain origin was also found in his right ventricle. With the diagnosis of acute limb ischemia (ALI), a thrombectomy and a bifemoral axillary bypass was established. The patient was transferred to the intensive care unit. Two days later he presented with muscular necrosis and collateral revascularization and right below knee amputation was performed. At 48 hours the patient suffered from febrile neutropenia, probably secondary to his immunosuppression and died. No signs of infection were found at the amputation stump.

Case 2, a 63 years old woman, under acenocoumarol treatment (within the desired range) due to atrial fibrillation (AF) was admitted in our hospital due to dyspnea associated to a previous diagnosis of COVID19. She would not have required previous oxygen support or any other invasive treatment other than thromboprophylaxis and steroids. She presented loss of strength and sensitivity as well as urinary sphincter's control. Acute thrombosis of the infrarenal aorta was diagnosed using CTA. A bifemoral axillary bypass was established with successful results. Hospital discharge took place some days later. Main radiological findings are shown in Figure 2.

Case 3, a 66 years old man with a recent ankle arthrodesis surgery in his right foot took advice at emergency department due to a 4 days clinical picture of edema and wound suppuration associated to anosmia and ageusia. He was not under anticoagulant treatment and COVID-19 infection was unexpectedly confirmed by RT-PCR test. He did never require oxygen support. He did also suffered loss of sensitivity and strength with lack of distal palpable pulse in his right ankle. A CTA, which we show in Figure 3, confirmed clinical suspicions of acute femoral ischemia. Local fibrinolysis and thrombectomy was performed without successful results, finally needing to have his right leg amputated. 
Case 4, a 85 years old woman, under dabigatran treatment due to AF was admitted at our hospital due to severe pain starting at her right gluteal region and reaching down to the knee. She presented loss of strength and sensitivity as well as coldness and paleness. She referred a similar clinical picture in the left leg a couple days before. It had been solved spontaneously. A CTA was requested and large filling defects were identified in infrarenal abdominal aorta and both common iliac arteries. Superior mesenteric, celiac and renal arteries were permeable. Moreover she had been hospitalized until 12 days before due to bilateral pneumonia secondary to SARS-CoV2. She did not present with a severe respiratory syndrome and did not require mechanical ventilation. Figure 4 demonstrates the main filling defects at aortic bifurcation and the occlusion of the common iliac arteries. Urgent surgery, bilateral transfemoral embolectomy, took place in order to remove the thrombi. After achieving satisfactory clinical results, she was discharged from hospital a few days later.

Table 2 shows main analytic parameters at time of arterial thrombosis diagnosis. Except for case 1, who was under chemotherapy because of his AML, blood count was normal in all cases. Moreover, all of them presented with elevated D-dimer levels. However, thrombophilia studies were performed in three of them and none showed positivity for antiphospholipid antibodies or factor V Leiden mutation. Other parameters related to prothrombotic status such as prothrombin time (PT) or S and C proteins were normal.

Table 2. Laboratory findings at the time of the thrombotic event. 


\begin{tabular}{|c|c|c|c|c|}
\hline & Case 1 & Case 2 & Case 3 & Case 4 \\
\hline \multicolumn{5}{|l|}{ Complete blood count } \\
\hline Hemoglobin $(g / d L)$ & 7.2 & 14.4 & 12.8 & 14.8 \\
\hline Platelet count $\left(\times 10^{3} / \mathrm{mm} 3\right)$ & 37 & 215 & 296 & 174 \\
\hline White cells $\left(\times 10^{3} / \mathrm{mm} 3\right)$ & 5,490 & 12,800 & 14,170 & 16,740 \\
\hline Lymphocytes $\left(\times 10^{3} / \mathrm{mm} 3\right)$ & 4,800 & 1,600 & 1,000 & 1,200 \\
\hline Neutrophils $\left(\times 10^{3} / \mathrm{mm} 3\right)$ & 400 & 10,200 & 12,600 & 14,600 \\
\hline \multicolumn{5}{|l|}{ Coagulation test } \\
\hline PT (sec) & 26 & 14 & $\mathrm{n}$ a & 11.4 \\
\hline INR & 2.2 & 1.24 & 1.34 & 1.06 \\
\hline aPTT (sec) & 24.1 & 25.3 & 28.5 & 28.2 \\
\hline$D$-dimer $(n g / m L)$ & 38,000 & 7,097 & 2,500 & 1,517 \\
\hline Fibrinogen $(m g / d L)$ & 824 & 656 & 1,020 & 912 \\
\hline $\mathrm{RCP}(\mathrm{mg} / \mathrm{dL})$ & 41 & 5.2 & 24.3 & 6.1 \\
\hline Ferritin (ng/mL) & 3,350 & 580 & 1,952 & $\mathrm{n}$ a \\
\hline Antiphospholipid antibodies & no & no & no & $\mathrm{n}$ a \\
\hline Factor V Leiden & no & no & no & $\mathrm{n} a$ \\
\hline Creatinine (mg/dL) & 0.9 & 1.47 & 1 & 0.4 \\
\hline LDH (U/L) & 4,400 & 980 & 495 & 274 \\
\hline Bilirubin $(\mathrm{mg} / \mathrm{dL})$ & 0.3 & 1 & 0.9 & $\mathrm{na}$ \\
\hline
\end{tabular}

PT, prothrombin time; $\mathrm{RCP}$, reactive-C protein; $\mathrm{LDH}$, Lactate dehydrogenase; $\mathbf{n}$ a; not available.

One last aspect we would like to point out is that except for case 3 , in which macroscopic findings compatible with atherosclerosis were found, the other 3 patients showed healthy arteries, with no evidence of pre-existing vessel lesions or atheroma surrounding the thrombi.

\section{Discussion And Conclusions}

An increase in morbidity and mortality due to thromboembolic events has been shown in patients suffering from COVID-19 infection [1]. The big rate of venous thromboembolism (VTE) has been widely 
highlighted, but few studies are focused on systemic arterial embolism [2]. There is a growing interest in determining the risk factors involved in the development of thrombosis [3].

On the one hand, different working groups have reported the relationship between age, gender, cardiovascular disease or cancer history and severity of SARS-CoV2 infection. We present herein two men and two women, whose median age was 69 years old.

Two of the most important retrospective studies taken place in Wuhan, China, showed a clear predominance of men over women in terms of severity and mortality as well as poorer outcomes in the oldest versus the younger patients [4,5]. Other cardiovascular risk factors such as diabetes, overweight, smoking and hypertension have been stablished as predictors of mortality due to COVID-19 $[4,6]$. It is also known that the risk of severe illness due to SARS-CoV2 infection is higher in patients with cancer history [7]. The cases we present support most of the outcomes previously described [4,5,7].

On the other hand, Zhang et al. have notified that thrombosis is caused by hypercoagulability due to antiphospholipid antibodies, that can arise transiently in patients with critical illness and infections [8]. However, none of the cases that we present here showed positivity in these tests. Moreover, Malentacchi et al. have reported cases of simultaneous occurrence of VTE and arterial thrombosis [9], but none of the patients we present here evolved in this way.

Furthermore, severity of respiratory symptoms and rate of thrombosis also seem to show some mismatch. To note, in contrast to the few studies taken place in our working environment, none of the patients we present with concomitant COVID-19 infection required invasive oxygen therapy. This observation makes an important difference in contrast to other cases reported, which show clear correlation $[10,11]$.

Additionally, we would like to emphasize that three of the patients we present developed arterial thrombosis independently of the use of antithrombotic treatment [11]. Two of our patients were receiving properly full (therapeutic) dose of anticoagulant therapy due to AF and another one had been receiving $\mathrm{LMWH}$ as prophylaxis until platelet count decreased below $30,000 / \mathrm{mm}^{3}$. Due to the above, the prophylactic use of low doses of acetylsalicylic acid (ASA) has been discussed by different groups. It is well known the anti-inflammatory and antithrombotic effect of ASA [12]. In addition to these effects of ASA, in vitro and experimental models support its capacity to reduce replication, propagation, and infectivity of several RNA-enveloped viruses, including human CoV-229E and MERS-CoV [13]. Thus, different working groups advocate the widespread use of ASA prophylactically in COVID19 infection $[13,14]$. Chow JH et al. described in a large cohort study of 412 COVID-19 infected patients that the use of ASA was independently associated with a lower risk of mechanical ventilation, ICU admission, and inhospital mortality [15]. Conversely, Aditya Sahai et al. hold that the use of traditional antiplatelet agents may not protect against thrombotic events or mortality in COVID-19 infection. When comparing two study groups, they find that ASA therapy was associated with an increased risk of thrombotic stroke $(3.6 \% \mathrm{vs}$ $0.40 \%, p=0.036)[16]$. 
Platelets have a wide range of critical functions and mechanisms of thrombosis in COVID-19 deserve further investigation. Drug trials are necessary to determine the real role ASA could play in these patients.

One more aspect we would like to point out is the unexpected location of the thrombi. Studies that report arterial thrombosis describe the main affected vascular territories. Limbs and mesenteric ischemia, as well as cerebral territories were the most frequently affected areas $[11,17,18]$. However, we present herein the concomitant finding of a right ventricle thrombus in one of the four patients. This special vascular bed has not been widely reported yet [19-21]. In most of the cases that have been described before, transthoracic echocardiogram (TTE) was obtained given the severity of hypoxemia and hemodynamic instability of patients [22-24]. As far as we know, this is the first case in which right ventricle thrombus was found in a patient with no invasive oxygen therapy or hemodynamic instability. It was an unexpected finding seen in the upper part of CTA performed to diagnose the abdominal aortic thrombosis. Given that the TTE is a minimally invasive test, it could be performed routinely in patients with COVID-19 infection and arterial thrombosis, in order to anticipate severe complications, such as ventricular thrombosis.

Finally, we would like to emphasize the poorly known mechanisms underlying microvascular thrombotic and inflammatory processes seen in patients suffering from COVID-19. Multiple studies have found that they may play an important role in exacerbating ADRS and extrapulmonary events in these patients [3,2528]. These deleterious complications likely result from dysfunction of the vascular endothelium [29]. Its dysregulation leads to vasoconstriction, hyperinflammation, vascular leakage, thrombosis and improper antiviral immune response. Moreover, endothelial dysregulation is a well stablished actor in reported COVID-19 comorbidities such as hypertension, obesity or diabetes [30-33]. In spite of the fact that abnormal coagulation and inflammation parameters provide evidence for endothelium dysregulation in severe COVID-19 patients, the pathophysiological mechanisms underlying this situation still require further clarification $[34,35]$. It seems clear, however, that SARS-CoV2 may use two related pathways; either directly through endothelial cell infection or indirectly through the infection of other susceptible cell types, which cause hyperinflammation and aberrant antiviral responses [25,27]. Reports of microangiopathic complications in severe COVID-19 support a role for immunothrombosis in viral pathogenesis. SARSCoV2 was recently found to promote pro-inflammatory complement activation in association with endothelial damage in severe COVID-19 [36,37]. This may promote the development of complementsuppressing therapeutics aimed at decreasing hyperinflammation in severe COVID-19 [38].

In conclusion, COVID-19 infection may predispose patients to an increased risk of thrombotic complications through different pathophysiological mechanisms, such as inflammation, immobilization, endothelial dysfunction, and a hypercoagulable state, all of them, still in need of deeper investigation. Further studies should focus on the rate and association of thromboembolic events and SARS-CoV2 infection and identifying the patients at higher risk for arterial thrombosis to determine the best preventive maneuvers.

\section{Abbreviations}


A: amputation

AF: atrial fibrillation

ALI: acute limb ischemia

AML: acute myeloid leukemia

Ao: aorta

ARDS: acute respiratory distress syndrome

ASA: acetylsalicylic acid

BAB: bifemoral axillary bypass

CF: common femoral

Cl: common iliac

COVID-19: coronavirus disease 2019

CTA: computed tomographic angiography

CV: cardiovascular

HIV: human immunodeficiency viruses

HT: hypertension

IAo: infrarenal aorta

LDH: lactate dehydrogenase

LF: left femoral

LFi: local fibrinolysis

LMWH: low-molecular-weight-heparin

na: not available

nd: new diagnosis

PCR: protein-chain-reaction

PT: prothrombin time 
r: remission

RCP: reactive-C protein

RP: right popliteal

$\mathrm{RV}$ : right ventricle

SARS-CoV2: severe acute respiratory syndrome coronavirus 2

TE: thrombectomy

TTE: transthoracic echocardiogram

VTE: venous thromboembolism

\section{Declarations}

\section{- Ethics approval and consent to participate.}

Ethical approval for this study has been sought. It has been approved by Fundación Jiménez Díaz University Hospital research ethics committee and has been performed in accordance with the ethical standards as laid down in the 1964 Declaration of Helsinki and its later amendments.

\section{- Consent for publication.}

Informed consent was obtained from all individual participants included in the study who were alive at that moment, according to the research ethics committee instructions.

\section{- Availability of data and materials.}

Not applicable.

\section{- Competing interests.}

The authors declare that they have no competing interests.

\section{- Funding.}

Not applicable.

\section{- Authors' contributions.}

SR and LS contributed equally to this work. The authors provided a diverse patient care among different institutions. 
Conception and design: SR, LS and PL.

Data collection: SR, LS and MT.

Data analysis: SR, LS, AR and PL.

Manuscript drafting: SR and LS.

Critical manuscript revision: all authors.

Final approval of the manuscript: all authors.

\section{- Acknowledgements.}

Authors expressed great gratitude to the patient support for our case report and to the Hematology and Radiology Department of Fundación Jiménez Díaz University Hospital in Madrid, Spain, for supporting this work.

\section{References}

1. Wang D, Hu B, Hu C, Zhu F, Liu X, Zhang J, et al. Clinical Characteristics of 138 Hospitalized Patients With 2019 Novel Coronavirus-Infected Pneumonia in Wuhan, China. JAMA [Internet]. 2020 Mar 17 [cited 2021 Jan 29];323(11):1061. Available from: https://jamanetwork.com/journals/jama/fullarticle/2761044

2. Klok FA, Kruip MJHA, van der Meer NJM, Arbous MS, Gommers DAMPJ, Kant KM, et al. Incidence of thrombotic complications in critically ill ICU patients with COVID-19. Thromb Res [Internet]. 2020 [cited 2021 Jan 28];191:145-7. Available from: http://www.ncbi.nlm.nih.gov/pubmed/32291094

3. Bikdeli B, Madhavan M V, Jimenez D, Chuich T, Dreyfus I, Driggin E, et al. COVID-19 and Thrombotic or Thromboembolic Disease: Implications for Prevention, Antithrombotic Therapy, and Follow-Up: JACC State-of-the-Art Review. J Am Coll Cardiol [Internet]. 2020 [cited 2021 Jan 29];75(23):2950-73. Available from: http://www.ncbi.nlm.nih.gov/pubmed/32311448

4. Zhou F, Yu T, Du R, Fan G, Liu Y, Liu Z, et al. Clinical course and risk factors for mortality of adult inpatients with COVID-19 in Wuhan, China: a retrospective cohort study. Lancet (London, England) [Internet]. 2020 Mar 28 [cited 2021 Feb 1];395(10229):1054-62. Available from: http://www.ncbi.nlm.nih.gov/pubmed/32171076

5. Ruan Q, Yang K, Wang W, Jiang L, Song J. Clinical predictors of mortality due to COVID-19 based on an analysis of data of 150 patients from Wuhan, China. Intensive Care Med [Internet]. 2020 [cited 2021 Feb 1];46(5):846-8. Available from: http://www.ncbi.nlm.nih.gov/pubmed/32125452

6. Kashi M, Jacquin A, Dakhil B, Zaimi R, Mahé E, Tella E, et al. Severe arterial thrombosis associated with Covid-19 infection. Thromb Res [Internet]. 2020 [cited 2021 Feb 1];192:75-7. Available from: http://www.ncbi.nlm.nih.gov/pubmed/32425264 
7. Yang F, Shi S, Zhu J, Shi J, Dai K, Chen X. Clinical characteristics and outcomes of cancer patients with COVID-19. J Med Virol [Internet]. 2020 Oct 2 [cited 2021 Jan 28];92(10):2067-73. Available from: https://onlinelibrary.wiley.com/doi/10.1002/jmv.25972

8. Zhang Y, Xiao M, Zhang S, Xia P, Cao W, Jiang W, et al. Coagulopathy and Antiphospholipid Antibodies in Patients with Covid-19. N Engl J Med [Internet]. 2020 Apr 23 [cited 2021 Jan 28];382(17):e38. Available from: http://www.nejm.org/doi/10.1056/NEJMc2007575

9. Malentacchi M, Gned D, Angelino V, Demichelis S, Perboni A, Veltri A, et al. Concomitant brain arterial and venous thrombosis in a COVID-19 patient. Eur J Neurol [Internet]. 2020 [cited 2021 Jan 28];27(9):e38-9. Available from: http://www.ncbi.nlm.nih.gov/pubmed/32503080

10. Gómez-Mesa JE, Galindo-Coral S, Montes MC, Muñoz Martin AJ. Thrombosis and Coagulopathy in COVID-19. Curr Probl Cardiol [Internet]. 2020 Nov 2 [cited 2021 Feb 1];100742. Available from: http://www.ncbi.nlm.nih.gov/pubmed/33243440

11. Gomez-Arbelaez D, Ibarra-Sanchez G, Garcia-Gutierrez A, Comanges-Yeboles A, Ansuategui-Vicente M, Gonzalez-Fajardo JA. COVID-19-Related Aortic Thrombosis: A Report of Four Cases. Ann Vasc Surg [Internet]. 2020 Aug [cited 2021 Jan 28];67:10-3. Available from: http://www.ncbi.nlm.nih.gov/pubmed/32474145

12. Undas A, Brummel-Ziedins KE, Mann KG. Antithrombotic properties of aspirin and resistance to aspirin: beyond strictly antiplatelet actions. Blood [Internet]. 2007 Mar 15 [cited 2021 Feb 14];109(6):2285-92. Available from: http://www.ncbi.nlm.nih.gov/pubmed/17148593

13. Bianconi V, Violi F, Fallarino F, Pignatelli P, Sahebkar A, Pirro M. Is Acetylsalicylic Acid a Safe and Potentially Useful Choice for Adult Patients with COVID-19? Drugs [Internet]. 2020 Sep 23 [cited 2021 Feb 17];80(14):1383-96. Available from: http://link.springer.com/10.1007/s40265-020-01365-1

14. Haque S, Jawed A, Akhter N, Dar SA, Khan F, Mandal RK, et al. Acetylsalicylic acid (Aspirin): a potent medicine for preventing COVID-19 deaths caused by thrombosis and pulmonary embolism. Eur Rev Med Pharmacol Sci [Internet]. 2020 [cited 2021 Feb 14];24(18):9244-5. Available from: http://www.ncbi.nlm.nih.gov/pubmed/33015764

15. Chow JH, Khanna AK, Kethireddy S, Yamane D, Levine A, Jackson AM, et al. Aspirin Use is Associated with Decreased Mechanical Ventilation, ICU Admission, and In-Hospital Mortality in Hospitalized Patients with COVID-19. Anesth Analg [Internet]. 2020 Oct 21 [cited 2021 Feb 14]; Available from: https://journals.Iww.com/10.1213/ANE.0000000000005292

16. Sahai A, Bhandari R, Koupenova M, Freedman J, Godwin M, McIntyre T, et al. SARS-CoV-2 Receptors are Expressed on Human Platelets and the Effect of Aspirin on Clinical Outcomes in COVID-19 Patients. Res Sq [Internet]. 2020 Dec 23 [cited 2021 Feb 17]; Available from: http://www.ncbi.nlm.nih.gov/pubmed/33398263

17. Reyes Valdivia A, Gómez Olmos C, Ocaña Guaita J, Gandarias Zúñiga C. Cardiovascular examination should also include peripheral arterial evaluation for COVID-19 patients. J Vasc Surg [Internet]. 2020 [cited 2021 Jan 28];72(2):758-60. Available from: http://www.ncbi.nlm.nih.gov/pubmed/32361070 
18. Mestres G, Puigmacià R, Blanco C, Yugueros X, Esturrica M, Riambau V. Risk of peripheral arterial thrombosis in COVID-19. J Vasc Surg [Internet]. 2020 [cited 2021 Jan 28];72(2):756-7. Available from: http://www.ncbi.nlm.nih.gov/pubmed/32417015

19. Khan HMW, Khan MR, Munir A, Moughrabieh A, Changezi HU. A Giant Right-Heart Thrombus-inTransit in a Patient with COVID-19 Pneumonia. Am J Case Rep [Internet]. 2020 Nov 17 [cited 2021 Feb 17];21:e927380. Available from: http://www.ncbi.nlm.nih.gov/pubmed/33201863

20. Elkattawy S, Younes I, Noori MAM. A Case Report of Polymerase Chain Reaction-Confirmed COVID-19 in a Patient With Right Ventricular Thrombus and Bilateral Deep Vein Thrombosis. Cureus [Internet]. 2020 Jun 15 [cited 2021 Feb 17];12(6):e8633. Available from:

http://www.ncbi.nlm.nih.gov/pubmed/32685302

21. Kaplan JG, Kanwal A, Malek R, Dickey JQ, Keirn R, Zweig B, et al. COVID-19 resulting in bilateral pulmonary emboli and a right ventricular thrombus: association or causation? A case report. Eur Hear journal Case reports [Internet]. 2020 Oct [cited 2021 Feb 17];4(5):1-5. Available from: http://www.ncbi.nlm.nih.gov/pubmed/33204989

22. Sethi SS, Zilinyi R, Green P, Eisenberger A, Brodie D, Agerstrand C, et al. Right Ventricular Clot in Transit in COVID-19: Implications for the Pulmonary Embolism Response Team. JACC Case reports [Internet]. 2020 Jul 15 [cited 2021 Feb 17];2(9):1391-6. Available from:

http://www.ncbi.nlm.nih.gov/pubmed/32835284

23. Sulemane S, Baltabaeva A, Barron AJ, Chester R, Rahman-Haley S. Acute pulmonary embolism in conjunction with intramural right ventricular thrombus in a SARS-CoV-2-positive patient. Eur Heart J Cardiovasc Imaging [Internet]. 2020 Sep 1 [cited 2021 Feb 17];21(9):1054. Available from: http://www.ncbi.nlm.nih.gov/pubmed/32338707

24. Kaki A, Singh H, Cohen G, Schreiber T. A case report of a large intracardiac thrombus in a COVID-19 patient managed with percutaneous thrombectomy and right ventricular mechanical circulatory support. Eur Hear journal Case reports [Internet]. 2020 Dec [cited 2021 Feb 17];4(6):1-5. Available from: http://www.ncbi.nlm.nih.gov/pubmed/33437917

25. Ackermann M, Verleden SE, Kuehnel M, Haverich A, Welte T, Laenger F, et al. Pulmonary Vascular Endothelialitis, Thrombosis, and Angiogenesis in Covid-19. N Engl J Med [Internet]. 2020 [cited 2021 Feb 25];383(2):120-8. Available from: http://www.ncbi.nlm.nih.gov/pubmed/32437596

26. Jung F, Krüger-Genge A, Franke RP, Hufert F, Küpper J-H. COVID-19 and the endothelium. Clin Hemorheol Microcirc [Internet]. 2020 [cited 2021 Feb 25];75(1):7-11. Available from: http://www.ncbi.nlm.nih.gov/pubmed/32568187

27. Pons S, Fodil S, Azoulay E, Zafrani L. The vascular endothelium: the cornerstone of organ dysfunction in severe SARS-CoV-2 infection. Crit Care [Internet]. 2020 Dec 16 [cited 2021 Feb 25];24(1):353. Available from: https://ccforum.biomedcentral.com/articles/10.1186/s13054-02003062-7

28. Desai R, Gandhi Z, Singh S, Sachdeva S, Manaktala P, Savani S, et al. Prevalence of Pulmonary Embolism in COVID-19: a Pooled Analysis. SN Compr Clin Med [Internet]. 2020 Oct 28 [cited 2021 
Feb 25];1-4. Available from: http://www.ncbi.nlm.nih.gov/pubmed/33145478

29. Sardu C, Gambardella J, Morelli MB, Wang X, Marfella R, Santulli G. Hypertension, Thrombosis, Kidney Failure, and Diabetes: Is COVID-19 an Endothelial Disease? A Comprehensive Evaluation of Clinical and Basic Evidence. J Clin Med [Internet]. 2020 May 11 [cited 2021 May 10];9(5):1417. Available from: https://www.mdpi.com/2077-0383/9/5/1417

30. Yau JW, Teoh H, Verma S. Endothelial cell control of thrombosis. BMC Cardiovasc Disord [Internet]. 2015 Oct 19 [cited 2021 May 10];15:130. Available from:

http://www.ncbi.nlm.nih.gov/pubmed/26481314

31. Jourde-Chiche N, Fakhouri F, Dou L, Bellien J, Burtey S, Frimat M, et al. Endothelium structure and function in kidney health and disease. Nat Rev Nephrol [Internet]. 2019 [cited 2021 May 10];15(2):87-108. Available from: http://www.ncbi.nlm.nih.gov/pubmed/30607032

32. Wardlaw JM, Smith C, Dichgans M. Small vessel disease: mechanisms and clinical implications. Lancet Neurol [Internet]. 2019 [cited 2021 May 10];18(7):684-96. Available from:

http://www.ncbi.nlm.nih.gov/pubmed/31097385

33. Sardu C, Gambardella J, Morelli MB, Wang X, Marfella R, Santulli G. Is COVID-19 an Endothelial Disease? Clinical and Basic Evidence. 2020 Apr 13 [cited 2021 Feb 25]; Available from: https://www.preprints.org/manuscript/202004.0204/v1

34. Bikdeli B, Madhavan M V, Jimenez D, Chuich T, Dreyfus I, Driggin E, et al. COVID-19 and Thrombotic or Thromboembolic Disease: Implications for Prevention, Antithrombotic Therapy, and Follow-Up: JACC State-of-the-Art Review. J Am Coll Cardiol [Internet]. 2020 [cited 2021 Feb 25];75(23):2950-73. Available from: http://www.ncbi.nlm.nih.gov/pubmed/32311448

35. Tang N, Li D, Wang X, Sun Z. Abnormal coagulation parameters are associated with poor prognosis in patients with novel coronavirus pneumonia. J Thromb Haemost [Internet]. 2020 [cited 2021 May 10];18(4):844-7. Available from: http://www.ncbi.nlm.nih.gov/pubmed/32073213

36. Cugno M, Meroni PL, Gualtierotti R, Griffini S, Grovetti E, Torri A, et al. Complement activation and endothelial perturbation parallel COVID-19 severity and activity. J Autoimmun [Internet]. 2021 [cited 2021 May 10];116:102560. Available from: http://www.ncbi.nlm.nih.gov/pubmed/33139116

37. Eriksson O, Hultström M, Persson B, Lipcsey M, Ekdahl KN, Nilsson B, et al. Mannose-Binding Lectin is Associated with Thrombosis and Coagulopathy in Critically III COVID-19 Patients. Thromb Haemost [Internet]. 2020 Dec [cited 2021 May 10];120(12):1720-4. Available from: http://www.ncbi.nlm.nih.gov/pubmed/32871607

38. Bernard I, Limonta D, Mahal LK, Hobman TC. Endothelium Infection and Dysregulation by SARS-CoV2: Evidence and Caveats in COVID-19. Viruses [Internet]. 2020 [cited 2021 May 10];13(1). Available from: http://www.ncbi.nlm.nih.gov/pubmed/33375371

\section{Figures}



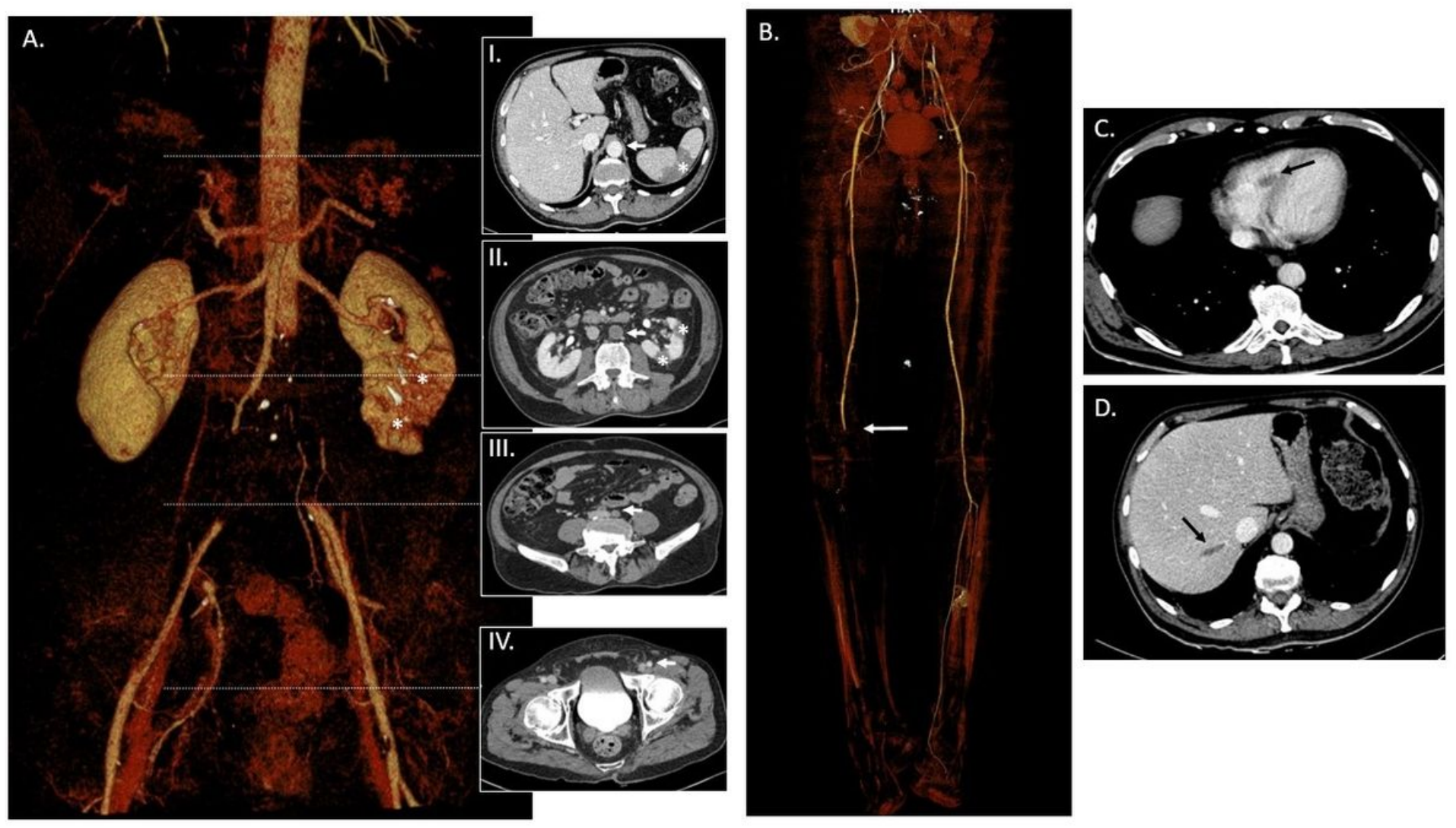

\section{Figure 1}

A. Computed tomography angiography (CTA) three-dimensional image shows extensive thrombosis of the infrarenal aorta with extension through common iliac arteries. Axial contrast-enhanced CT images show a patent/ permeable suprarenal aorta (arrow in I), and an occlusive infrarenal aortic filling defect (arrow in II) extended through common iliac arteries (arrow in III) with repermeabilization of the contrast pool at the level of femoral arteries (arrow in IV). It is remarkable that there is not a significant pre-existing aortic atherosclerosis. A contrast-enhanced CT scan also reveals perfusion defects $\left.{ }^{*}\right)$ in the spleen (I) and in the left kidney (II) consistent with infarcts. B. CT angiography (CTA) three-dimensional image of the lower extremities shows occlusion of the right popliteal artery (arrow). There is no evidence of arterial perfusion below the right knee. C. Axial CT image demonstrates a thrombus (black arrow) in the right ventricle and in the right hepatic vein (black arrow) in $\mathrm{D}$. 


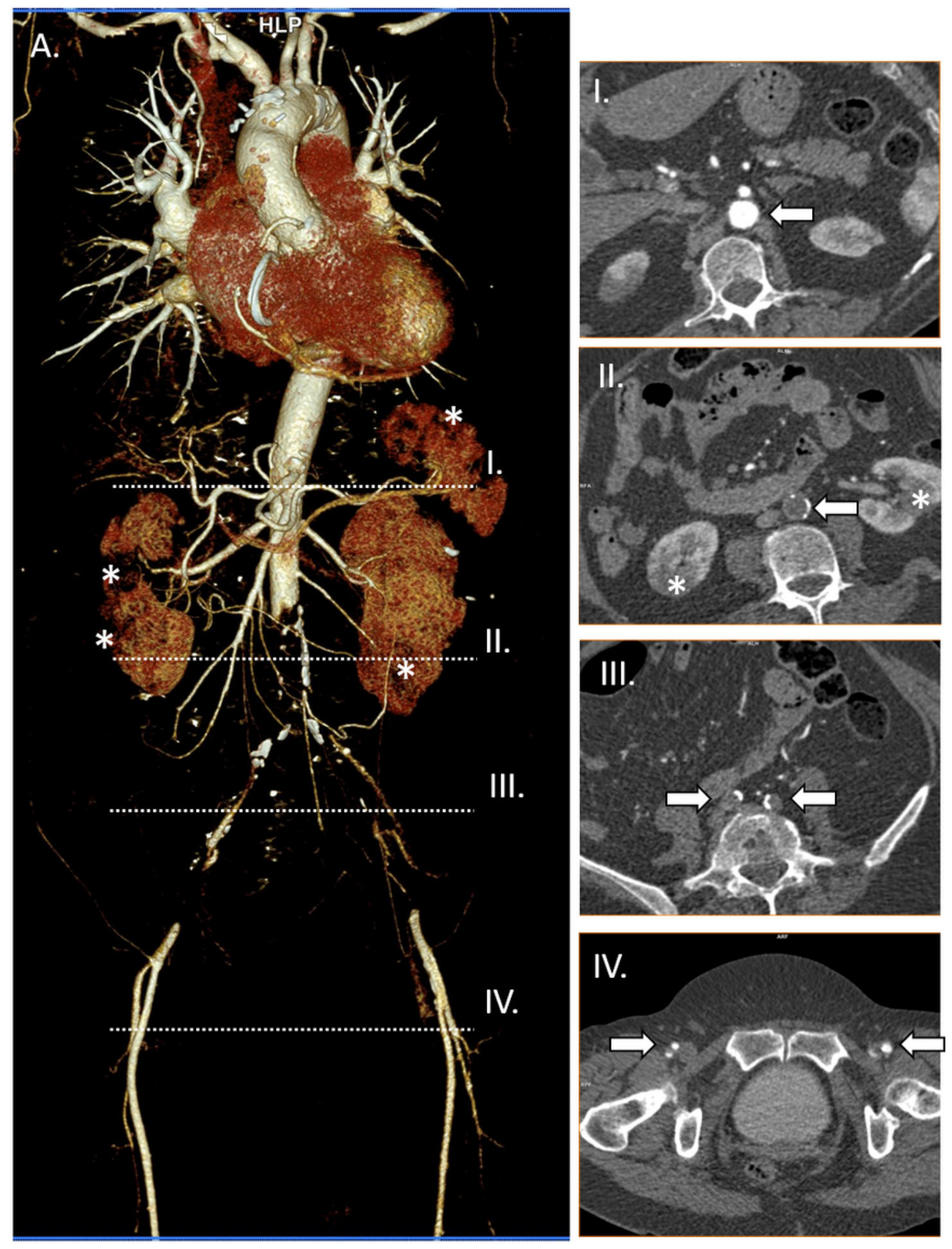

\section{Figure 2}

Computed tomography angiography (CTA) three-dimensional image and axial contrast-enhanced CT images shows extensive thrombosis of the infrarenal aorta (in II) with extension through common internal and external iliac arteries (arrows in III) with repermeabilization in the common femoral arteries (arrows in IV). A contrast-enhanced CT scan also reveals perfusion defects (*) in the spleen and in both kidneys. 

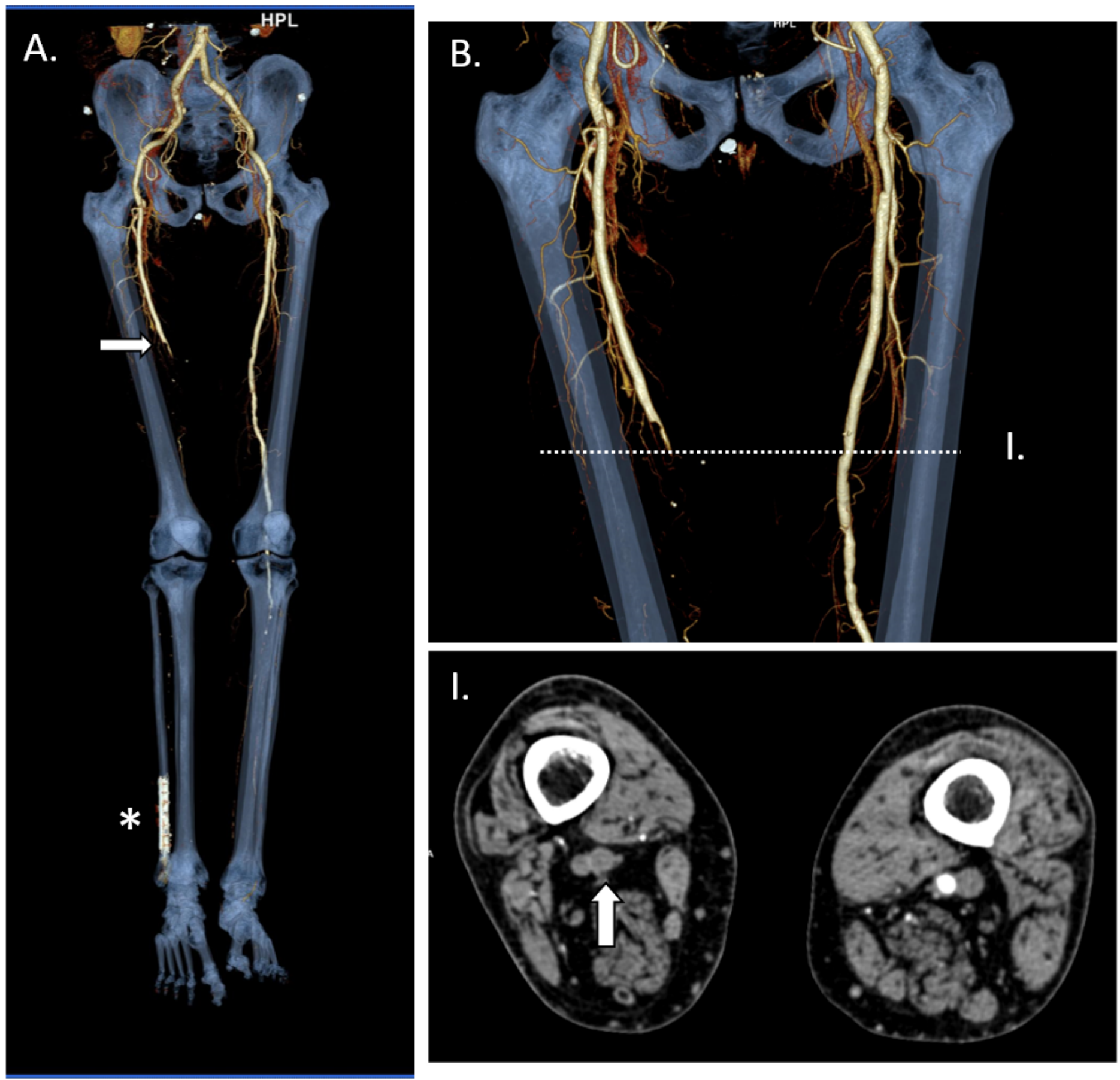

Figure 3

Computed tomography angiography (CTA) three-dimensional image $(A, B)$ shows narrowing of the lumen and occlusion of the right superficial femoral artery (arrow without opacification of the distal vessels. (*, ankle arthrodesis). Axial contrast-enhanced CT images (I) show an acute occlusive thrombus in the right superficial femoral artery (arrow). 

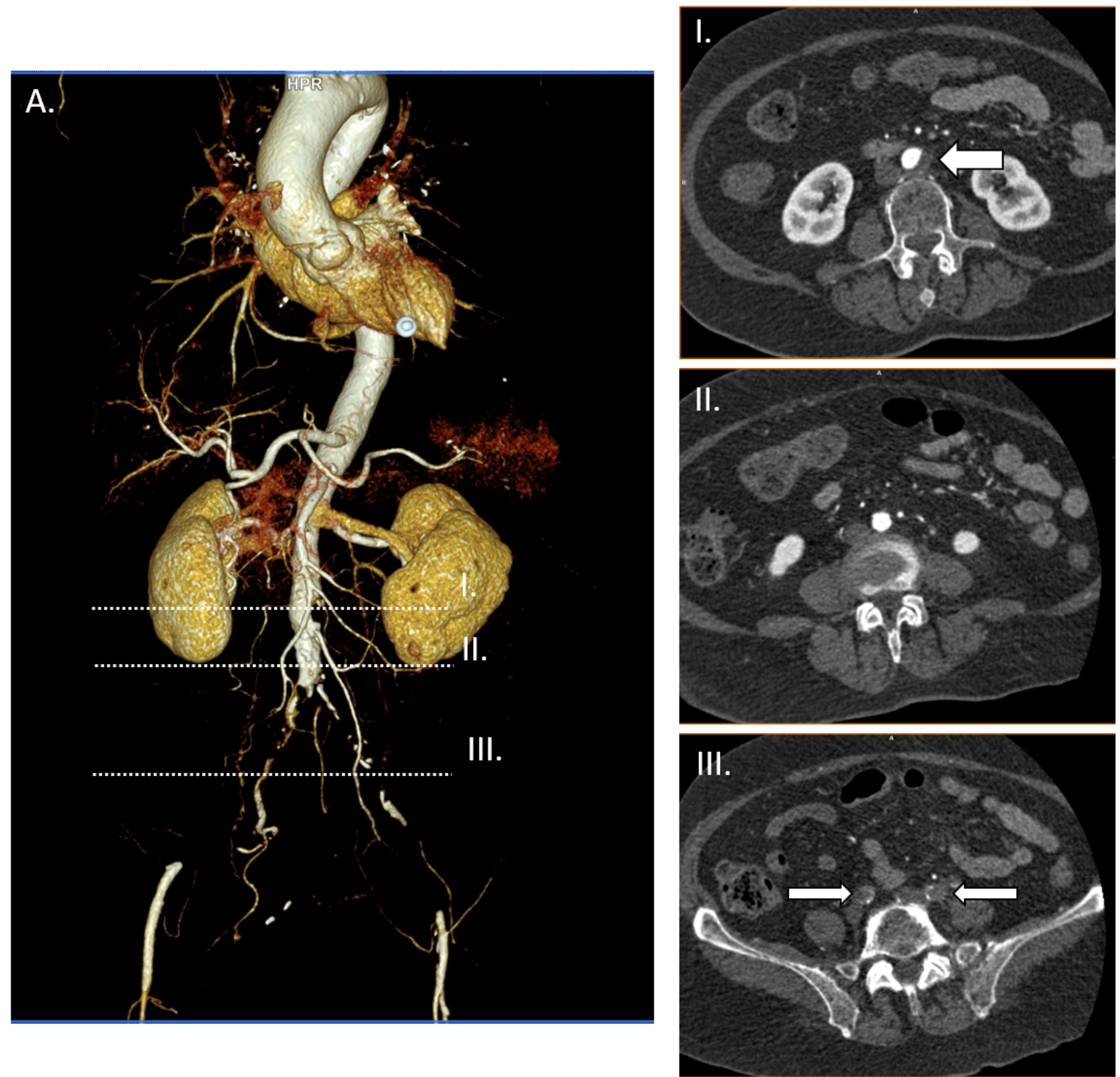

Figure 4

A. Computed tomography angiography (CTA) three-dimensional image demonstrates a thrombotic obliteration of the aortic bifurcation with extension through common iliac arteries. Axial contrastenhanced CT images show a non-occlusive arterial thrombi in the intrarenal aorta above the bifurcation (arrow in I) and the occlusion of the common iliac arteries (arrows in III). 